http://www.jumdc.com/

Original Article

\title{
Effectiveness of muscle energy technique (met) in patients with acute low back pain: Qusai experimental Study
}

\section{Muhammad Usman Khalida, Danish Hassan ${ }^{\mathrm{b}}$, Yasir kazmic, Muhammad Hassan ${ }^{\mathrm{a}}$, Haroon Mansha $^{a}$, Hayatullah khalid ${ }^{\mathrm{a}}$}

aAssistant Professor, Department of Physiotherapy, College of Physiotherapy Multan Medical and Dental College Multan.

${ }^{\mathrm{b}}$ Assistant Professor, Department of Physiotherapy, Riphah International University Lahore Campus.

'Assistant Professor, Department of Physiotherapy, Shahida Islam Medical College of Rehabilitation Sciences Lodhran.

*Corresponding author: dr.usman_khalid@yahoo.com

\section{ABSTRACT}

BACKGROUND \& OBJECTIVE: Low back pain is a common problem in society. Acute low back pain can persist for up to six weeks and requires immediate attention for treatment. The muscle energy technique was mostly used in rehabilitation for strengthening and relaxation purposes. The objective of the study was to find out the effectiveness of the muscle energy technique in patients with acute low back pain.

METHODOLOGY: It was a quasi-experimental study; with a sample size of 60 were collected from 05 June 2020 to 05 November 2020. A convenient sampling technique was used and patients were divided into two groups after inclusion and exclusion criteria. The tools were the Standardized visual analog scale (VAS) and Oswestry disability index (ODI). The setting was Ibn e Siena Hospital and Research Institute, Multan and Multi-care physiotherapy clinic Multan. An Independent t-test was applied to measure the significance of data. The experimental group was treated by muscle energy technique and the control group was treated through neuromuscular control exercises.

RESULTS: Total number of patients in the study was 60, equally divided into two groups. Pre and post control and experiment group ODI mean \pm SD $28.13 \pm 5.25,12.66 \pm 3.78$ and $26.13 \pm 4.12,7.80 \pm 3.14$, pre and post-VAS $8.70 \pm 0.79,8.30 \pm$ 1.17 and $2.00 \pm 1.20,0.76 \pm 1.00$ respectively. There was a significant difference $(\mathrm{p}<0.000)$ between a pre and post intervention score of the Oswestry disability index (ODI) and the visual analog scale (VAS).

CONCLUSION: Muscle energy technique was more effective than neuromuscular control exercises in mechanical acute low back pain.

KEYWORDS: Exercise, Low Back Pain, Lumbar vertebrae, Manual Therapy, Neuromuscular Control.

\section{INTRODUCTION}

Acute mechanical low back pain (LBP) is defined as back pain that mostly arises from the spinal joints, discs and spinal soft tissue without any severe pathology ${ }^{[1]}$. Low back pain is a common neuromuscular problem, affecting $40 \%$ of the population at some point in their life, which causes disability. Low back pain can be classified as acute, subacute, and chronic ${ }^{[2]}$.

In many cases, the cause of low back pain is unidentified, when this type of pain occurs it is believed that this is mechanical low back pain, sprain, or strain ${ }^{[3]}$. The first management of low back pain is medication such as NSAID is recommended for pain relief ${ }^{[4]}$. Some Opioids may be used for pain management but are generally not recommended due to side effects ${ }^{[5]}$. Surgical intervention is recommended for the severity of the disease, such as vertebral disc causing chronic pain and deformity or stenosis of the spine ${ }^{[5-7]}$. Strengthening and Core stability exercises (CSEs) are considered as the treatment option for non-specific mechanical low back pain by strengthening the lumbar multifidus and transverse abdominal muscles ${ }^{[8]}$. Many theories say that low back pain occurs due to poor lumbar segment stability ${ }^{[9]}$. Isometric exercises are another treatment option for spinal stability; these exercises are applied gently to maximum contraction, and varying muscle lengths, by altering joint angles as well as the strength improved by isometric exercises. It also increases the sporting performance of muscles. Isotonic exercises are those exercises in which tension remains the same by the change of muscle's length. Isotonic exercises are useful for the improvement of muscles strength and endurance ${ }^{[10]}$.

Khalid MU, Hassan D, Kazmi Y, Hassan M, Mansha H, Khalid H. Effectiveness of muscle energy technique (met) in patients with acute low back pain: Qusai experimental trial. Journal of University Medical \& Dental College.2022;13(1):325-328. 
The bad posture also leads to lower back pain. More than one hour of sitting have also a risk factor for low back pain. A bad postural sitting and working environment combined with awkward and non-ergonomically sitting postures contribute to low back pain ${ }^{[11]}$. A study was conducted on Iranian automotive industry office workers that showed about $19.7 \%$ were suffering from low back pain ${ }^{[12]}$.

There is a significant association between lumbosacral and radicular pain. Many case-control studies showed a positive relationship between body mass index (BMI) and lumbar disc herniation in both gender ${ }^{[13]}$. One of the common causes of acute low back pain is disc herniation ${ }^{[14]}$. A pilot study conducted in 2003 suggests that MET has a great effect on the reduction of disability and improving the functional level of the participant with acute low back pain ${ }^{[15]}$.

The objective of the study was to find out the effectiveness of muscle energy techniques with acute low back pain. The rationale of this study was to promote MET in acute conditions of low back pain. The hypothesis of the study was muscle energy technique (MET) and neuromuscular control in patients with acute low back pain were or were not equally effective.

\section{METHODOLOGY}

The topic was approved by the ethical committee with reference no. RCR\&AHS/REC/MSOMPT/32. It was a quasi-experimental trial, a sample size of 60 patients with acute mechanical low back pain not more than three months were included. The setting was Ibn e Siena Hospital and Research Institute, Multan, and Multi-care physiotherapy clinic Multan. The study duration was 05 June 2020 to 05 November 2020. Informed consent was taken by the patients before the data collection. A convenient sampling technique was used to divide the patients into two groups after inclusion and exclusion criteria. Standardized visual analog scale (VAS) and Oswestry disability index (ODI) were used $[16,17]$. The experimental group was treated by muscle energy technique and the control group was treated through neuromuscular control exercises.

The study comprised patients who had acute mechanical low back pain for at least 4 weeks at the time of evaluation, were between the ages of 18 and 65 , and did not have symptoms radiating to the lumbar, buttocks, or lower extremities.

Patients with spinal tumours, post-surgery back pain, back pain onset after the accident, and pregnant women with low back pain were excluded from the study.

One patient in the control group and two patients in the experimental group were not able to continue the treatment. Baseline data were collected from both groups before the start of treatment. Patients were given 5 sessions in a week for a total of 3 weeks. After the completion of 15-sessions, patients were reevaluated with VAS and ODI.

Experimental group patients were treated with muscle energy technique (MET), applying the hot pack and TENS for 15 minutes. MET was performed as described by $b$ Greenman, patient on side-lying on the opposite side of the flexion and side bending restriction ${ }^{[15]}$. The patients were also trained and given a home exercise plan that included "placing the restricted side foot on a stool or chair to create a 90-degree angle of hip and knee, gently bending forward, and rotating to the restricted side."

Control group patients were treated by applying the hot pack and TENS for 15 minutes followed by the stretching exercises of the low back, including the knee to chest unilateral and bilateral bending in the supine lying position and bridging was included as a strengthening exercise. Home exercise plan was taught to the patients, as knee to chest unilateral and bilateral bending in the supine lying position. The data normality distribution was checked by the Shapiro Wilk test and an independent t-test was used to analyze the data. Change in the score was noted by this formula ${ }^{[15]}$.

\section{$\underline{\text { Pretreatment score - Post-treatment score x } 100}$} Pretreatment score

\section{RESULTS}

Table-I: Descriptive statistics.

\begin{tabular}{cccc}
\hline \multicolumn{2}{c}{ Control group } & \multicolumn{2}{c}{ Experimental group } \\
\hline $\mathbf{N}$ & 30 & $\mathrm{~N}$ & 30 \\
\hline Age(Mean \pm SD) & $37.03 \pm 12.16$ & Age & $36.76 \pm 11.12$ \\
Male n(\%) & $21(70 \%)$ & Male & $21(70 \%)$ \\
\hline Female $\mathbf{n}(\%)$ & $9(30 \%)$ & Female & $9(30 \%)$ \\
\hline
\end{tabular}

The data were analyzed using an independent t-test. The total patients in the study were 60 in numbers, equally divided into two groups. Among them 21 (70\%) were male and $9(30 \%)$ were females in each group. The mean age of the control and experimental groups were $37.03 \pm 12.16$, $36.76 \pm 11.12$ respectively. Mean scores for pre-ODI were $28.13 \pm 5.25$ and $26.13 \pm 4.12$ and for post-ODI were $12.66 \pm$ 3.78 and $7.80 \pm 3.14$. The p-value (i.e. $<0.001$ ) of ODI posttreatment $<0.05$ shows a significant difference. The mean scores for pre-VAS were $8.70 \pm 0.79$ and $8.30 \pm 1.17$ and for post-VAS were $2.00 \pm 1.20$ and $0.76 \pm 1.00$. The p-value (i.e. $<0.001$ ) of VAS post-treatment $<0.05$ shows a significant difference.

\section{DISCUSSION}

Acute LBP is a problem that required immediate attention for treatment which is cost-effective worldwide ${ }^{[18]}$. Mechanical acute low back pain rehabilitation programs must be a focus on an intensive, progressive resistance training exercise, to restore the normal function of the spine. This treatment regime became popular recently to improve the functional status of the patients. Now it is clear that passive care is not an effective treatment option for the care of mechanical acute low back pain which has, a negative effect on the patient health status and is more costly on the health system [19].

The results of this study support MET with neuromuscular 
Table-II: Pre and post ODI and VAS.

\begin{tabular}{ccccccccc}
\hline \multicolumn{2}{c}{ ODI } & & & & \multicolumn{2}{c}{ VAS } \\
\hline Mean Score & \multicolumn{2}{c}{ Mean \pm SD } & p-value & Mean Score & \multicolumn{2}{c}{ Mean \pm SD } & p-value \\
& Control & Experiment & & & Control & Experiment & \\
Pre ODI & $28.13 \pm 5.25$ & $26.13 \pm 4.12$ & 0.107 & Pre VAS & $8.70 \pm 0.79$ & $2.00 \pm 1.20$ & 0.129 \\
\hline Post-ODI & $12.66 \pm 3.78$ & $7.80 \pm 3.14$ & $<0.001$ & Post VAS & $8.30 \pm 1.17$ & $0.76 \pm 1.00$ & $<0.001$ \\
\hline
\end{tabular}

control exercises that give the dual benefits of the lower back which are (a) strengthen (b) relaxation for those structures having spasms which are aggravated by the activities of prolonged sitting, standing, and stooping posture ${ }^{[20]}$.

MET with neuromuscular reeducation and strengthening techniques have a greater effect for the reduction of disability and improving the function level of the participant with acute condition low back pain ${ }^{[15]}$. The results of both studies are the same which shows that the METs with neuromuscular exercises are a more effective treatment option for the acute low back. The population of this study is very small and results required further studies for the strong evidence to apply as additional manual therapy techniques in acute low back pain. This study has a great focus on this and can be applied in acute lumber conditions.

Nowadays MET is widely used by osteopaths in Australia and United Kingdom ${ }^{[21]}$. MET is used as a component of a treatment option in multiple studies. A single study was found for the MET application in acute low back pain which has a low-risk bias. This study has a small group of 20 participants that showed low-level evidence ${ }^{[22]}$.

Another study explained that the use of other physical therapy interventions of the soft tissue technique such as spinal manipulation is beneficial for acute low back pain. American osteopaths also recommended that MET should be used for low back pain and the integrity of the soft structures of the back ${ }^{[22,23]}$.

\section{CONCLUSION}

When compared to neuromuscular control exercises, the muscle energy approach was more effective and improved the functional status of patients with acute low back pain.

ACKNOWLEDGEMENT: None. CONFLICT OF INTEREST: None.

GRANT SUPPORT \& FINANCIAL DISCLOSURE: None.

\section{REFERENCE}

1. Wáng YX, Wáng JQ, Káplár Z. Increased low back pain prevalence in females than in males after menopause age: evidences based on synthetic literature review. Quantitative Imaging in Medicine and Surgery. 2016;6(2):199-206. Doi: 10.21037/qims.2016.04.06

2. Traeger A, Buchbinder R, Harris I, Maher C. Diagnosis and management of low-back pain in primary care. Canadian Medical Association Journal. 2017;189(45):E1386-E1395.
3. Figueredo R. Back Muscle Endurance as Measure by Ito Test Duration. 2017.

4. Qaseem A, Wilt TJ, McLean RM, Forciea MA. Noninvasive treatments for acute, subacute, and chronic low back pain: a clinical practice guideline from the American College of Physicians. Annals of Internal Medicine. 2017;166(7):514-530.

5. Miller SM. Low back pain: pharmacologic management. Primary Care-Clinics in Office Practice. $2012 ; 39(3): 499-510$.

6. Tahir M, Rehman L, Bokhari I, Ahmed SI, Afzal A. Surgical Outcome of Decompression and Fixation of Degenerative Lumbosacral Spondylolisthesis Surgery in Pakistani Population. Cureus. 2019;11(8). Doi: 10.7759/cureus.5493

7. Takahashi H, Suzuki T. Erector spinae plane block for low back pain in failed back surgery syndrome: a case report. Journal of Anesthesia clinical Reports. 2018;4(1):1-4. Doi:10.1186/s40981-018-0198-6

8. Pincus T, Smeets RJ, Simmonds MJ, Sullivan MJ. The fear avoidance model disentangled: improving the clinical utility of the fear avoidance model. The Clinical Journal of Pain. 2010;26(9):739-746.

9. Asfour S. Spine Biomechanics: A Review of Current Approaches. Spine. 2015;1(1):4.

10. Unver F, Alarab A. Isotonic versus isometric exercises on core muscle in patients with low back pain. Annals of Physical and Rehabilitation Medicine. 2018;61:e156.

11. Korshøj M, Hallman DM, Mathiassen SE, Aadahl M, Holtermann A, Jørgensen MB. Is objectively measured sitting at work associated with low-back pain? A cross sectional study in the DPhacto cohort. Scandinavian Journal of work, Environment \& Health. 2018:196-105.

12. Ghaffari M. Low back pain among industrial workers: Occupational health studies on prevalence, incidence, and associations with work and lifestyle in IR Iran. Institutionen för folkhälsovetenskap/Department of Public Health Sciences; 2007.

13. Schumann B, Bolm-Audorff U, Bergmann A, Ellegast R, Elsner G, Grifka J, et al. Lifestyle factors and lumbar disc disease: results of a German multi-center casecontrol study (EPILIFT). Arthritis Research \& Therapy. 2010;12(5):1-8.

14. Ali AM, Shahzad E. Risk factors of Lower back pain; a very common problem in Pakistani community. Asian Journal of Multidisciplinary Studies. 2019;7:11.

15. Wilson E, Payton O, Donegan-Shoaf L, Dec K. Muscle energy technique in patients with acute low back pain: a pilot clinical trial. Journal of Orthopaedic \& sports Physical therapy. 2003;33(9):502-512. Doi/10.2519/ jospt.2003.33.9.502 
16. Chenot JF, Greitemann B, Kladny B, Petzke F, Pfingsten M, Schorr SG. Nichtspezifischer Kreuzschmerz. Dtsch Arztebl International. 2017;114(51-52):883-890.

17. Fairbank JC, Pynsent PB. The Oswestry disability index. Spine. 2000;25(22):2940-2953.

18. Fritz JM, Kim M, Magel JS, Asche CV. Costeffectiveness of primary care management with or without early physical therapy for acute low back pain: economic evaluation of a randomized clinical trial. Spine. 2017;42(5):285-290.

19. Chenot JF, Greitemann B, Kladny B, Petzke F, Pfingsten M, Schorr SG. Nichtspezifischer Kreuzschmerz. Dtsch Arztebl International. 2017;114(51-52):883-890.

20. Gillani S, Rehman S, Masood T. Effects of eccentric muscle energy technique versus static stretching exercises in the management of cervical dysfunction in upper cross syndrome: a randomized control trial. Journal of the Pakistan Medical Association. 2020;70(3):1.

21. Orrock PJ, Myers SP. Osteopathic intervention in chronic non-specific low back pain: a systematic review. BMC Musculoskeletal Disorders. 2013;14(1):1-7.

22. Selkow NM, Grindstaff TL, Cross KM, Pugh K, Hertel J, Saliba S. Short-term effect of muscle energy technique on pain in individuals with non-specific lumbopelvic pain: a pilot study. Journal of Manual \& Manipulative Therapy. 2009;17(1):14E-8E.

23. Manzoor A, Anwar N, Haider R, Saghir M, Javed MA. Comparison of effectiveness of muscle energy technique with Mulligan mobilization in patients with non-specific neck pain. JPMA. The Journal of the Pakistan Medical Association. 2021;71(6):1532-1524.

\section{Author's Contribution:}

Muhammad Usman Khalid: Conception and design, revising it critically for intellectual content, final approval.

Danish Hassan: Acquisition of data, interpretation of data, final approval.

Yasir kazmi: Acquisition of data, analysis of data, drafting the article, final approval.

Muhammad Hassan: Designed the analysis and corrections. Haroon Mansha: Conceived and designed the analysis. Proof reading of the manuscript.

Hayatullah khalid: Overall supervisor of the project.

Submitted for publication: 22-09-2021

Accepted after revision: 19-01-2022 